\title{
Importance of the Mitral Subvalvular Apparatus for Left Ventricular Functional Anatomy
}

\author{
By \\ Nilgün Ulusoy BOZBUĞA ${ }^{1}$, Kayhan ŞAHİNOĞLU ${ }^{2}$, Zafer ARI ${ }^{2}$, \\ Adnan ÖZTÜRK ${ }^{2}$, Bülent BAYRAKTAR ${ }^{2}$, Ömer IŞIK ${ }^{1}$ and Cevat YAKUT ${ }^{1}$ \\ ${ }^{1}$ Department of Cardiovascular Surgery, Koşuyolu Heart and Research Hospital, Istanbul, Turkey \\ ${ }^{2}$ Department of Anatomy, Istanbul Medical Faculty, Istanbul University, Istanbul, Turkey \\ - Received for Publication, April 20, 1998 -
}

Key Words: Mitral subvalvular apparatus, Left ventricle, Functional anatomy

\begin{abstract}
Summary: The mitral subvalvular apparatus is so important to attain the integrity of the left ventricular geometric model and sistolic pump function of the heart. We conducted a detailed dissection of the anatomic structure of mitral valve complex and left ventricle of $\mathbf{1 0}$ adult hearts from fixed human cadavers (eight male and two female) at Department of Anatomy, Faculty of Medicine of İstanbul University and Department of Cardiovascular Surgery, Koşuyolu Heart and Research Hospital. The distribution of chordae tendinea and classification of musculus papillaris were recorded. The distribution of chordae tendinea varied slightly both anterior and posterior groups. Musculus papillaris was not simetrical in all subjects. Four type of musculus papillaris were distinguished. The insertio angulus of musculus papillaris varied between $20^{\circ}$ and $55^{\circ}$. The left ventricular distances (inflow-outflow) and axes (short-long) were determined as the criteria, together with the mitral subvalvular apparatus, to gain the architecture of the left ventricle. We believe that the goal a more precise data collection and developed model will influence our understanding of functional anatomy of left ventricular subvalvular apparatus, and concept of changes in left ventricular configuration after mitral valve surgery.
\end{abstract}

The mitral valve is an integral part of the left ventricle so its anatomical presence plays an essential role in the left ventricular geometry and mechanics $^{7}$. The mitral valve is not only a plain heart valve for prevention of back flow during left ventricular ejection, but also functional part of a very complex pumping chamber ${ }^{12,24)}$. The mitral valve leaflets are connected to the left ventricle wall by annulus, chordae tendineae and papillary muscles. Papillary muscles are considered as branches of the intramural myocardial fibers which originate from the atrio-ventricular ring, head towards to apex, rise up again and radiate into the papillary muscles $^{3,14}$. All these elements work together to make a functional unit, supporting the ejection of blood during systole.

\section{Material and Methods}

Ten human hearts were obtained from fixed human cadavers (eight male and two female) who had expired due to noncardiac causes. Ten human hearts were dissected to elucidate the clinical anatomy of these purportedly anatomosurgical segments together with the arrengement of left ventricular architecture.

The left atrium was open and then a catheter was inserted through the aortic outflow tract, and saline solution was injected to pressurize the left ventricle and check for any regurgitation or incompetence due to chordal or leaflet abnormalities. The left ventricle was entered transaortic route. The left venricle wall was opened from anterior wall through left ventricle outflow tract (Fig. 1).

The distribution of chordae tendinea was analyzed by categorizing each chordal structure, noting the following:

1) the insertion to the valve structure (anterior or posterior leaflet)

2) the location in relation to the leaflet edge (marginal, secondary, basal), 
3) the number of each group (anterior marginal, anterior secondary, posterior marginal, posterior secondary, posterior basal).

Musculus papillaris anterolateralis and Musculus papillaris posteromedialis classification and measurements were recorded by each division, noting the following:

1) the relationship between the heads and chordal distribution,

2) the number and the type of each papillary muscle subdivision,

3 ) the insertio angulus between papillary muscles.

Four types of musculus papillaris were identified $^{21,26)}$. In Type I musculus papillaris was single. In Type II musculus papillaris had two heads, one of which sent chordae exclusively to the posterior leaflet. In Type III musculus papillaris was also divided, one head supporting the commissural area exclusively. Type IV musculus papillaris was rather complex than Type III (Fig. 2).

All diameter measurements were performed by laying 4-0 suture along the dimension to be measured and then the suture was pulled straight and compared to a compass.

Left ventricular measurements were made of the following structural dimentions:

1) the inflow distance (mitral valve to apex)

2) the outflow distance (apex to aortic valve)

3) the short axis (musculus papillaris level)

4) the long axis (mitral leaflets level)

\section{Results}

The mitral subvalvular structures records were analyzed according the parameters which were de- scribed above.

The distribution of chordae tendineae varied slightly both anterior and posterior groups (Table $1)$. The number of anterior marginal chordae tendineae was ranged 3 to 6 (mean: 4.5 ). The number of anterior secondary chordae tendineae was ranged 3 to 4 (mean: 3.8 ). The number of posterior marginal chordae tendineae was ranged 4 to 10 (mean: 5.2). The number of posterior secondary chordae tendineae was ranged 3 to 14 (mean: 4.7). The number of posterior basal chordae tendineae was ranged 0 to 7 (mean: 3.3). The distribution of posterior chordae tendineae were determined in large range due to posterior leaflet scallops. Most chordal origins from both papillary muscles split to insert into the valve leaflets at both marginal and secondary positions.

Musculus papillaris were not simetrical in all subjects. Four type of musculus papillaris were distinguished (Table 1).

Type I: This type of musculus papillaris was undivided. Type I was observed $20 \%$ (in 2) of anterolateral papillary muscles, and $0 \%$ (in 0 ) of posteromedial papillary muscles.

Type II: This type of musculus papillaris was divided along a sagital plane into two heads. One head supported the posterior leaflet exclusively. The other head was releated to the commissural region and to the anterior leaflet. Type II was the most common presentation and observed $60 \%$ (in 6) of anterolateral papillary muscles, and $50 \%$ (in 5) of posteromedial papillary muscles.

Type III: This type of musculus papillaris was divided in a coronal plane into multiple heads. A single head related to the commissural zone. The remaining heads supported the chordae to the anterior and posterior leaflets. The different heads

Table 1. Chordal distribution and papillary muscle classification

\begin{tabular}{lcccccccc}
\hline NO & A Mar Ch & A Sec Ch & P Mar Ch & P Sec Ch & P Ba Ch & PM Angle & AL PM & PM PM \\
\hline 1 & 4 & 4 & 5 & 4 & 3 & $30^{\circ}$ & I & II \\
2 & 4 & 3 & 5 & 4 & 2 & $25^{\circ}$ & II & II \\
3 & 3 & 3 & 5 & 3 & 2 & $20^{\circ}$ & II & II \\
4 & 4 & 4 & 5 & 4 & 1 & $30^{\circ}$ & III & III \\
5 & 4 & 4 & 10 & 14 & 6 & $25^{\circ}$ & II & III \\
6 & 5 & 4 & 4 & 4 & 7 & $40^{\circ}$ & I & IV \\
7 & 6 & 4 & 6 & 5 & 0 & $55^{\circ}$ & II & II \\
8 & 5 & 4 & 4 & 3 & 4 & $20^{\circ}$ & IV & IV \\
9 & 5 & 4 & 4 & 3 & 4 & $25^{\circ}$ & II & III \\
10 & 5 & 4 & 4 & 3 & 4 & $35^{\circ}$ & II & II \\
AVERAGE & 4,5 & 3,8 & 5,2 & 4,7 & 3,3 & $31^{\circ}$ & & \\
MIN & 3 & 3 & 4 & 3 & 0 & $20^{\circ}$ & & \\
MAX & 6 & 4 & 10 & 14 & 7 & $55^{\circ}$ & & \\
MEDIAN & 5 & 4 & 5 & 4 & 4 & $28^{\circ}$ & II & II \\
\hline
\end{tabular}

A: Anterior, Mar Ch: Marginal Chordae Tendineae, P: Posterior, Sec Ch: Secondary Chordae Tendineae, PM: Papillary Muscles, Ba Ch: Basal Chordae Tendineae. 
Table 2. Left ventricular dimensions

\begin{tabular}{lllll}
\hline NO & $\begin{array}{l}\text { INFLOW } \\
(\mathrm{mm})\end{array}$ & $\begin{array}{l}\text { OUTFLOW } \\
(\mathrm{mm})\end{array}$ & $\begin{array}{l}\text { SHORT AXIS } \\
(\mathrm{mm})\end{array}$ & $\begin{array}{l}\text { LONG AXIS } \\
(\mathrm{mm})\end{array}$ \\
\hline 1 & 67,00 & 76,00 & 22,00 & 32,00 \\
2 & 72,00 & 87,00 & 28,00 & 32,00 \\
3 & 62,00 & 67,00 & 23,00 & 26,00 \\
4 & 63,00 & 80,00 & 31,00 & 45,00 \\
5 & 78,00 & 82,00 & 38,00 & 42,00 \\
6 & 78,00 & 91,00 & 48,00 & 52,00 \\
7 & 70,00 & 79,00 & 41,00 & 48,00 \\
8 & 81,00 & 81,00 & 42,00 & 47,00 \\
9 & 71,00 & 80,00 & 38,00 & 41,00 \\
10 & 72,00 & 81,00 & 31,00 & 40,00 \\
AVERAGE & 71,14 & 80,38 & 34,13 & 40,50 \\
MIN & 62,00 & 67,00 & 22,00 & 26,00 \\
MAX & 81,00 & 91,00 & 48,00 & 52,00 \\
MEDIAN & 71,00 & 80,50 & 34,50 & 43,50 \\
\hline
\end{tabular}

originated from the same level on the ventricular wall. Type III was observed $10 \%$ (in 1) of anterolateral papillary muscles, and $30 \%$ (in 3 ) of posteromedial papillary muscles.

Type IV: This type of musculus papillaris was complex and characteried by division along coronal plane and by staged origin of the different heads. Type IV was observed $10 \%$ (in 1) of anterolateral papillary muscles, and $20 \%$ (in 2) of posteromedial papillary muscles.

The insertio angulus of musculus papillaris varied in a large range between $20^{\circ}$ and $55^{\circ}$. The mean was $30.63^{\circ}$ and the median was $27.50^{\circ}$.

The left ventricular geometry depended on certain dimentions (Table 2). The mean inflow distances (mitral valve to apex) of left ventricle was found $71.4 \mathrm{~mm}$ (ranged 62 to $81 \mathrm{~mm}$ ). The outflow distance (apex to aortic valve) of left ventricle was found $80.4 \mathrm{~mm}$ (ranged 67 to $91 \mathrm{~mm}$ ).

The mean short axis (papillary muscles level) of left ventricle was measured $34.1 \mathrm{~mm}$ (ranged 22 to $48 \mathrm{~mm}$ ) and the mean long axis of left ventricle was measured $40.5 \mathrm{~mm}$ (ranged 26 to $52 \mathrm{~mm}$ ).

The left ventricular distances (inflow-outflow) and axes (short-long) were determined as the criteria, together with the mitral subvalvular apparatus, of architecture of the left ventricle.

\section{Discussion}

If advances in cardiac surgery are to continue into the twenty-first century, it will be necessery to concentrate on details of matters especially anatomy of the heart ${ }^{13,15,18)}$. Cadaveric studies are the basis for surgical anatomy and new surgical methods before they are applied in patients ${ }^{1)}$. Our data provides insight into mitral valve structure and function.

First publications on the surgical anatomy of the mitral apparatus were by Brock and Rusted in $1952^{2,23)}$. More knowledge about the morphology of mitral subvalvular apparatus was published by authors throughout the 60 's ${ }^{5.8)}$. In the early 70 's, Lam and Ranaganthan introduced the mitral valve nomenclature that has been accepted widely in cardiac surgery ${ }^{17,22)}$.

Left ventricular function improves if the continuity between the papillary muscles and leaflets is preserved in mitral valve operations ${ }^{4,16,25}$. Authors have noted a significant reduction of the ejection fraction in patients with mitral regurgitation after mitral valve replacement (MVR) without preservation of the subvalvular apparatus ${ }^{19.27)}$. Cardiac function after MVR for chronic mitral regurgitation has been reported to be impaired owing to postoperative elevation of left ventricular afterload and postoperative management of severe cases using conventional MVR is sometimes troublesome ${ }^{6}$.

During conventional mitral valve replacement, leaflets, chordae tendineae and part of musculus papillaris are resected. If the subvalvular apparatus is excited, the left ventricle will be no longer stabilized in the major axis, and its size and shape are altered. The polygon of the forces in the left ventricle has broken up by loss of the anchoring point of the mitral valve apparatus. The left ventricular geometry and architecture are changed by resection procedure ${ }^{9,10)}$. The mitral annulus is a dynamic structure that undergoes alterations in size and shape throughout the cardiac cycle, contracting during systole. Numerous reports have shown this systolic orifice reduction to be due mainly to posterior annular contraction, whereas the anterior perimeter was unchanged during left ventricular 
ejection ${ }^{11}$. The systolic motion of the mitral annulus is very important for normal mitral valvular function and closely linked to overall left ventricular systolic function. The upward displacement of the anterior mitral annulus away from the left ventricular apex at end-systole may possibly minimize resistance to left ventricle outflow during ejection ${ }^{20)}$.

We believe that the goal a more precise data collection and developed model will influence our understanding of left ventricular subvalvular apparatus, and concept of changes in left ventricular geometry after mitral valve surgery. The aim of this study was to obtain further understanding and knowledge about not only mitral valve functional anatomy, but also mitral valve pathology.

\section{Acknowledgements}

We specially thank to Associate Professor Murat Dikmen, M.Dt. for his concerning about material selection.

\section{References}

1) Anderson $\mathrm{RH}$ and Wilcox BR. Understanding cardiac anatomy: the prerequisite for optimal cardiac surgery. Ann Thorac Surg 1995; 59:1366-75.

2) Brock RC. The surgical and pathological anatomy of the mitral valve. British Heart J 1952; 14:489.

3) Campbell KB, Taheri H, Kirkpatrick RD, Burton T and Hunter WC. Similarities between dynamic elastence of left ventricular chamber and papillary muscle of rabbit heart Am J Physiol 1993; 264(6 Pt 2):H1926-41.

4) Carpentier AF, Lessana A, Relland JYM, Belli E, Mihaileanu S, Berrebi AJ, Palsky $\mathrm{E}$ and Loulmet DF. The "physio-ring": an advanced concept in mitral valve annuloplasty. Ann Thorac Surg 1995; 60:1177-86.

5) Chiechi MA, Less $\mathrm{Wm}$ and Thompson $R$. Functional anatomy of the normal mitral valve. J Thoracic Surgery 1956; 32:378-98.

6) David TE, Uden DE and Stuss HD. The importance of the mitral apparatus in left ventricular function after correction of mitral regurgitation. Circulation 1983; (2 Pt 2): 68:II7682.

7) Dean JW, Ho SY, Rowland E, Mann J and Anderson RH. Clinical anatomy of the atrioventricular junctions. J Am Coll Cardiol 1994; 24:1725-31.

8) Du Plesis LA and Marchand P. The anatomy of mitral valve and its associated structures. Thorax 1964; 19:221-7.

9) Gams E, Hagl S, Schad H, Heimisch W, Mendler N and Sebening F. Importance of the mitral apparatus for left ventricular function: an experimental approach. Eur J Cardiothorac Surg 1992; 6:17-23.

10) Gams E, Schad H, Heimisch W, Hagl S, Mendler N and
Sebening F. Importance of the left ventricular apparatus for cardiac performance. J Heart Valve Dis 1993; 2:624-5.

11) Glasson JR, Komeda M, Daugters GT, Niczyporuk MA, Bolger AF, Ingels NB and Miller DC. Three-dimentional regional dynamics of the normal mitral anulus during left ventricular ejection. J Thorac Cardiovasc Surg 1996; 111:574-85.

12) Hansen DE, Cahill PD and DeCampli WM. Valvular-ventricular interaction: importance of the mitral apparatus in canine left ventricular systolic performance. Circulation 1986; 73:1310-20.

13) Kumar N, Kumar M and Duran CMG. A revised terminology for recording surgical findings of the mitral valve. $J$ Heart Valve Dis 1995; 4:70-5.

14) Kunzelman KS and Cochran RP. Mechanical properties of basal and marginal mitral valve chordae tendinea. ASAIO Trans 1990; 36:M405-8.

15) Kunzelman KS, Cocran RP, Chuong C, Ring WS, Verrier ED and Eberhart RD. Finite element analysis of the mitral valve. J Heart Valve Dis 1993; 2:326-40.

16) Kunzelman KS, Cochran RP, Verrier ED and Eberhart RC. Anatomic basis for mitral valve modelling. J Heart Valve Dis $1994 ;$ 3:491-6.

17) Lam JHC, Ranganathan N, Wigle ED and Silver MD. Morphology of the human mitral valve. I - Chordea tendineae: a new classification. Circulation 1970; 41:449-58.

18) Miyairi $T$, Matsumoto $J$, Tanaka $K$ and Mizuno A. Intraoperative assessment of functioning mitral valve. Ann Thorac Surg 1996; 61:743-5.

19) Natsuaki M, Itoh T, Tomita S, Furukawa K, Yoshikai M, Suda $\mathrm{H}$ and Ohteki $\mathrm{H}$. Importance of preserving the mitral subvalvular apparatus in mitral valve replacement. Ann Thorac Surg 1996; 61:585-90.

20) Pai RG, Tanimoto $M$, Jintapakorn $W$, Azevedo J, Pandian NG and Shah PM. Volume-rendered three-dimentional dynamic anatomy of the mitral annulus using a transesophageal echocardiographic technique. J Heart Valve Dis 1995; 4:623-7.

21) Ramsheyi SA, Pargaonkar, Lassau JP and Acar C. Morphologic classification of the mitral papillary muscles. J Heart Valve Dis 1996; 5:472-6.

22) Ranganathan N, Lam JHC, Wigle ED and Silver MD. Morphology of the human mitral valve. II - The valve leaflet. Circulation 1970; 41:459-67.

23) Rusted IE, Scheifley $\mathrm{CH}$ and Edwards JE. Studies of the mitral valve. I - Anatomic features of the normal mitral valve and associated structures. Circulation 1952; 6:825-83.

24) Sarris GE, Fann JI, Niczyporuc MA, Derby GC, Harden $\mathrm{CE}$ and Miller DC. Global and regional left ventricular performance in the in-situ ejecting canine heart: importance of the mitral apparatus. Circulation $1989 ; 8(1 \mathrm{Pt}$ 2):I24-42.

25) van Rijk-Zwikker GL, Delemarre BJ and Huysman HA. Mitral valve anatomy and morphology: Relevance to mitral valve replacement and valve reconstruction. J Card Surg 1994; 9(Suppl):255-61.

26) Victor $S$ and Nayak VM. Variation in papillary muscles of normal mitral valve and their surgical relevance. J Card Surg 1995; 10:597-607.

27) Yun KL, Rayhill SC and Niczyporuc MA. Mitral valve replacement in dilated canine hearts with chronic mitral regurgitation: importance of the mitral subvalvular apparatus. Circulation 1991; 84(3 Pt 2):III112-24. 


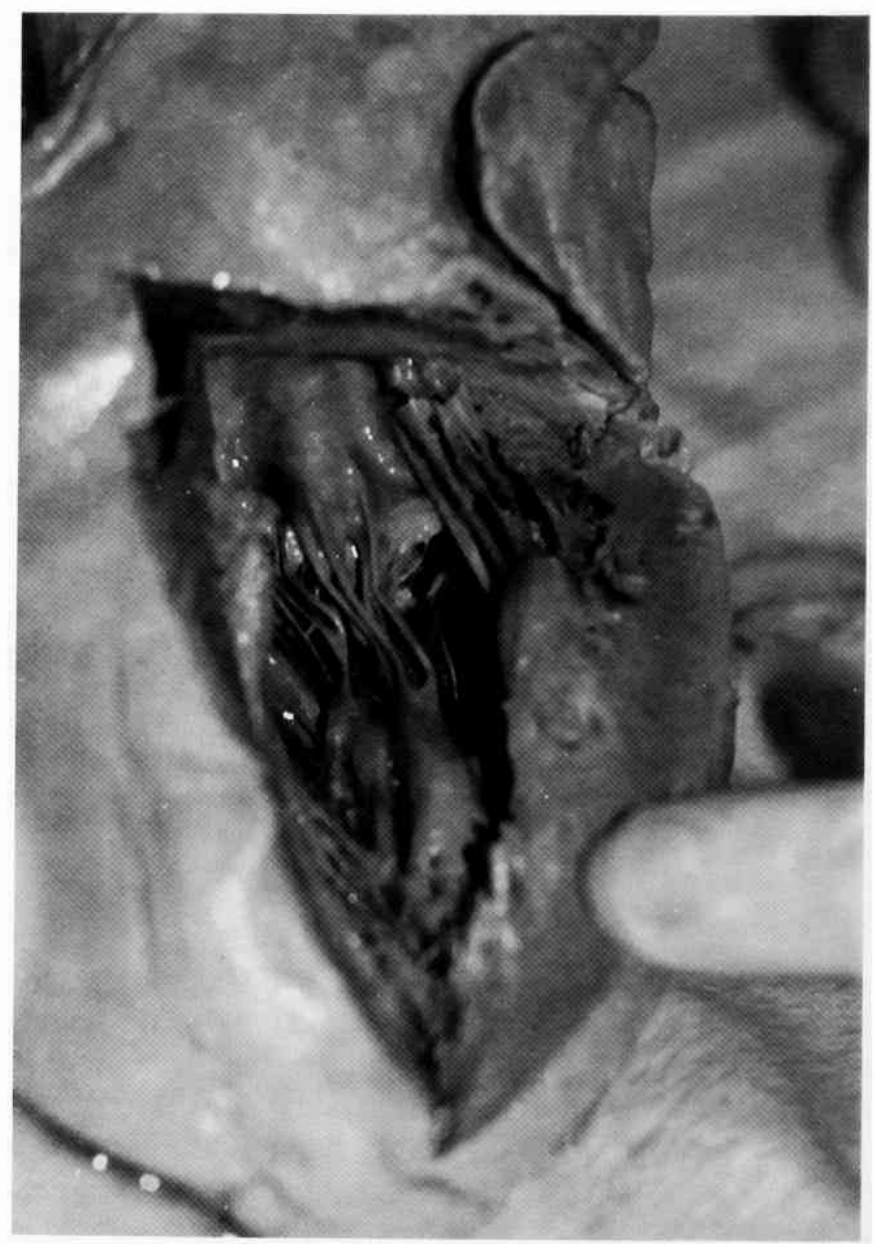

\section{Explanation of Figures}

\section{Plate I}

Fig. 1. The mitral subvalvular apparatus through left ventriculectomy. 
Plate II

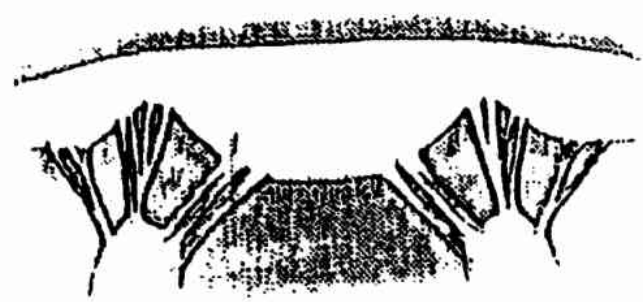

1

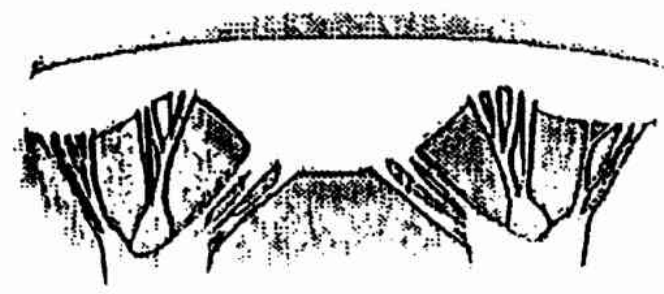

III

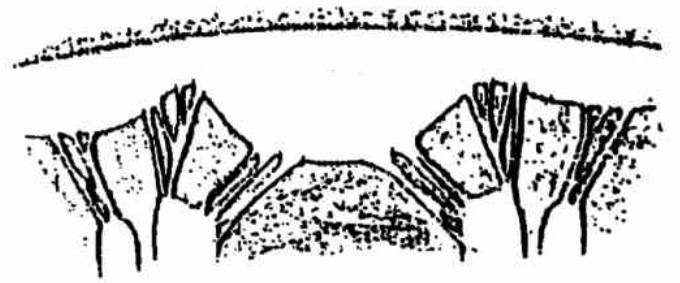

II

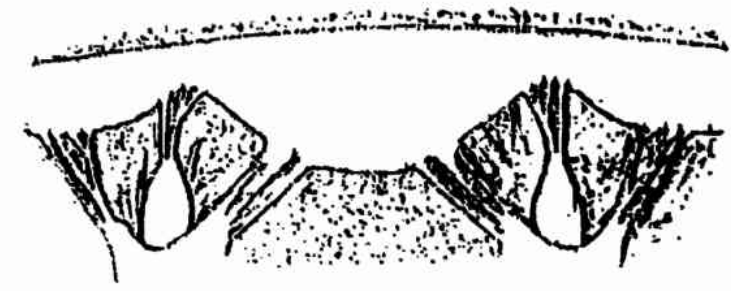

Iv

Plate II

Fig. 2. The papillary muscles classification. 